\title{
CORRELATION OF HEMOGLOBIN A1C AND DIABETES RISK USING THE THAI DIABETES RISK SCORE
}

Wyn Parksook*, Preamrudee Chaisuwirat **, Apussanee Boonyavarakul*

*Division of Endocrinology, Department of Internal Medicine, Phramongkutklao Hospital, Bangkok, Thailand

** Blood Bank, Army Institute of Pathology, Phramongkutklao Medical Center, Bangkok, Thailand

\begin{abstract}
Background: Early detection of diabetes allows prompt access to interventions that can improve microvascular and macrovascular disease outcomes. Multiple strategies have been employed, i.e., the use of diabetes risk scores including blood testing.

Objective: The study aimed to evaluate the correlation between point-of-care hemoglobin A1c (POC $\mathrm{HbAlc)}$ and Thai diabetes risk score.

Methods: A cross-sectional study was conducted consisting of 252 individuals without diabetes over the age of 35. Demographic data and anthropometric measures were recorded and the blood test for POC HbAlc including plasma glucose were performed.

Results: Of 252 participants, the mean HbA1c was $5.56 \pm 0.73 \%$, the median Thai diabetes risk score was 7 [5-10] and American Diabetes Association (ADA) risk score was 3 [2.3-4]. Males had higher risk scores than females. Weak positive correlations were observed between POC HbA1c and both Thai and ADA risk score $(r=0.226$ and 0.279 , respectively, $p<0.001)$. The predictors of higher HbAlc among males were high BMI and waist circumference.

Conclusion: A weak correlation of POC HbAlc and Thai diabetes risk score suggested that POC HbA1c may not be beneficial in screening diabetes in out-of-clinic situations; however, male participants with WC $>100 \mathrm{~cm}$ and $\mathrm{BMI}>27.5 \mathrm{~kg} / \mathrm{m}^{2}$ were associated with highest $\mathrm{HbA} 1 \mathrm{c}$.
\end{abstract}

Keywords: Type 2 diabetes, Diabetes risk score, HbA1c, Point-of-care, Screening

J Southeast Asian Med Res 2021: 5(1):42-50

http://www.jseamed.org

Correspondence to:

Parksook W, Department of Internal Medicine, Phramongkutklao Hospital, Bangkok, Thailand

E-mail:wynparksook@hotmail.com

Received: 09 February 2021

Revised: 29 May 2021

Accepted: 09 June 2021 


\section{Introduction}

Type 2 diabetes mellitus is one of more prevalent noncommunicable diseases with increasing prevalence yearly. The International Diabetes Federation (IDF) estimated that diabetes affected 463 million individuals globally. ${ }^{(1)}$ In Thailand, the prevalence of diabetes among adults is $7.0 \%$ and is estimated to increase to $8.0 \%$ by 2045. ${ }^{(2)}$ Of those affected, $43.6 \%$ remain unaware of their diabetic conditions.

Due to the silent nature of the disease, diabetes often goes undetected. The lack of adequate interventions and monitoring until late into the disease progression results in microvascular and macrovascular complications. ${ }^{(3)}$ These include diabetic retinopathy, neuropathy, nephropathy and cardiovascular atherosclerosis. The chronic and additive clinical progression of diabetes means that cost of care increases over time, as demonstrated in a recent UK Prospective Diabetes Study (UKPDS) 84.(4) It would be prudent; therefore, to detect diabetes at the earliest phase so intervention result could reduce complications and mortality.
High risk screening for diabetes has been the mainstay strategy for early detection and has been adopted in a number of guidelines. The Thai Clinical Practice Guidelines for Diabetes 2017 has endorsed a risk score system devised by Aekplakorn et al. ${ }^{(5)}$ This cohort study has good accuracy in predicting 12-year risk of new-onset diabetes (Table 1). ${ }^{(6)}$ The maximum score is 17. When the score is 6 or more, further diabetes evaluation is warranted. Waist circumference and BMI are classified according to WHO definitions.

In the absence of risk factors, Thai guidelines also suggested blood tests for diabetes among individuals over the age of 35 with these following conditions: $\mathrm{BMI} \geq 25 \mathrm{~kg} / \mathrm{m}^{2}$, increased waist circumference, first degree relatives having diabetes, hypertension, dyslipidemia, prior gestational diabetes (GDM) or when delivering a child $>4 \mathrm{~kg}$, cardiovascular disease or polycystic ovarian syndrome. ${ }^{(5)}$ Studies in other countries validated diabetes risk scores that correlate to their specific populations. The American Diabetes Association (ADA) is one of the major guidelines in the US having its own risk score. ${ }^{(7)}$

Table 1. Type 2 diabetes risk score

\begin{tabular}{|c|c|}
\hline Risk Factor & Diabetes Risk Score \\
\hline \multicolumn{2}{|l|}{ Age } \\
\hline $34-39$ years & 0 \\
\hline $40-44$ years & 0 \\
\hline $45-49$ years & 1 \\
\hline$\geq 50$ years & 2 \\
\hline \multicolumn{2}{|l|}{ Gender } \\
\hline Female & 0 \\
\hline Male & 2 \\
\hline \multicolumn{2}{|l|}{ Body mass index (BMI) } \\
\hline$<23 \mathrm{~kg} / \mathrm{m}^{2}$ & 0 \\
\hline $23-27.5 \mathrm{~kg} / \mathrm{m}^{2}$ & 3 \\
\hline$>27.5 \mathrm{~kg} / \mathrm{m}^{2}$ & 5 \\
\hline \multicolumn{2}{|l|}{ Waist circumference } \\
\hline Males $<90 \mathrm{~cm}$, Females $<80 \mathrm{~cm}$ & 0 \\
\hline Males $\geq 90 \mathrm{~cm}$, Females $\geq 80 \mathrm{~cm}$ & 2 \\
\hline \multicolumn{2}{|l|}{ Hypertension } \\
\hline No & 0 \\
\hline Yes & 2 \\
\hline \multicolumn{2}{|l|}{ Family history DM } \\
\hline No & 0 \\
\hline Yes & 4 \\
\hline
\end{tabular}


Screening of diabetes requires elevated fasting plasma glucose (FPG) or fasting capillary blood glucose $(\mathrm{FCBG}) \geq 126 \mathrm{mg} / \mathrm{dL}$, which has to be repeated once. ${ }^{(7)}$ However, hemoglobin A1c (HbAlc) has not yet been implemented in the Thai guidelines. ${ }^{(5)}$ Alternatively, $75 \mathrm{~g}$ oral glucose tolerance test (OGTT) can be used which has higher sensitivity than fasting glucose ${ }^{(8)}$ However, due to its invasive and time-consuming nature, OGTT is not routinely practiced.

Diagnostic cut off points are similar in all guidelines, requiring two abnormal values for diagnosis. However, the accuracy of HbAlc can vary as over 300 different protocols are available to measure $\mathrm{HbAlc} .^{(9,10)}$ The heterogeneity of $\mathrm{HbAlc}$ has been addressed and a number of organizations have endeavored to standardize $\mathrm{HbAl}$. This includes the National Glycohemoglobin Standardization Program (NGSP), International Federation of Clinical Chemistry (IFCC), Mono-S, and Japanese Society of Clinical Chemistry/Japanese Diabetes Society (JSCC/JDS). The IFCC-NGSP master equation is the current accepted standards for HbA1c. ${ }^{(11,12)}$ The limitation of diabetes screening and risk score use is they are usually evaluated at a doctor's clinic. Even when individuals have routine check-ups, not evaluating other risks and lifestyle, diabetes diagnosis can be missed.

The aim of this study was to evaluate the correlation between POC HbAlc and diabetes risk score, endorsed by the Thai diabetes clinical practice guidelines among blood donors. Additionally, the correlation between ADA diabetes risk score and the measured POC HbAlc was also investigated.

\section{Methods}

This study was approved by the Institutional Review Board, Medical Department, Royal Thai Army. Informed consent was signed by all study participants. Individuals, donating blood at the Blood Bank, Pathology Institute, Phramongkutklao Medical Center, were asked to participate in this study. According to the published IDF Diabetes, the prevalence of impaired glucose tolerance (IGT) was 15.5. ${ }^{(13)}$ To calculate the sample size powered to include diabetes and IGT, a minimum of 202 individuals were necessary to provide a $95 \%$ confidence interval at the margin of error of
$5 \%$. The inclusion criteria were individual blood donors without type 2 diabetes, and aged 35 years or older who had given inform consent. Those who had prior diabetes, hemoglobinopathy, untreated hypothyroidism, chronic liver, chronic kidney diseases, prior splenectomy, received blood transfusion in the past four months, or routinely took supplements of iron, folic acid, vitamin B12 or vitamin $\mathrm{E}$ in the past three months were excluded.

All participants were asked to fill in a questionnaire designed to assess individual demographics, anthropometric and lifestyle measures. Blood collection was taken at the time of blood donor screening. Aside from the blood tests required for routine blood donation, hemoglobin, serum creatinine and POC HbAlc (cobas b 101, Roche Diagnostics) were also collected. The Thai diabetes risk score was derived from the study using Aekplakorn et al. ${ }^{(6)}$ In addition, the ADA diabetes risk score was also used for comparison.

\section{Definitions}

Diabetes is defined as FPG $\geq 126 \mathrm{mg} / \mathrm{dL}, 75 \mathrm{~g}$ OGTT $\geq 200 \mathrm{mg} / \mathrm{dL}$, and $\mathrm{HbA} 1 \mathrm{c} \geq 6.5 \%$. Prediabetes is defined as FPG $100-125 \mathrm{mg} / \mathrm{dL}, 75 \mathrm{~g}$ OGTT 140-199 mg/dL, and HbAlc 5.7-6.4\%. Dietary control is defined as the self-perceived attitude in an individual's diet in glycemic and hypertensive control. Regular exercise is defined as regular physical activity for at least 30 minutes daily for three to five days weekly.

\section{Statistical analysis}

Statistical analysis was performed using SPSS Software, Version 23.0 (SPSS Inc, Chicago, USA) with significance at $p<0.05$. Normality of data was assessed using the one-sample Kolmogorov -Smirnov test. Normally distributed data were expressed as mean \pm standard deviation (SD) and nonnormal data were expressed as median (interquartile range). Correlations were evaluated using two-tailed Pearson's tests. The Mann -Whitney test was used to analyze the differences between risk categories of the diabetes risk scores. 


\section{Results}

A total of 273 individuals agreed to participate in the study. After excluding 21 participants having type 2 diabetes, 252 people were recruited in the study. Of these, 137 (54.4\%) were male. The majority of participants $(86.1 \%)$ did not fast before blood collection. None reported having chronic kidney disease, cardiovascular disease or stroke. No significant differences between sexes were found; however, male participants had higher diabetes risk according to both Thai and ADA scores. Baseline characteristics of participants are shown in Table 2.

Table 2. Baseline clinical characteristics of enrolled participants

\begin{tabular}{|c|c|c|c|}
\hline & $\begin{array}{l}\text { All Individuals } \\
(\mathrm{n}=\mathbf{2 5 2})\end{array}$ & $\begin{array}{c}\text { Female Individuals } \\
(\mathrm{n}=115)\end{array}$ & $\begin{array}{l}\text { Male Individuals } \\
\quad(\mathrm{n}=\mathbf{1 3 7})\end{array}$ \\
\hline \multicolumn{4}{|l|}{ Clinical } \\
\hline Age (years, mean \pm SD) & $44.2 \pm 7.28$ & $44.23 \pm 7.10$ & $44.1 \pm 7.45$ \\
\hline$\leq 44$ years & 151 & 69 & 82 \\
\hline $45-49$ years & 44 & 18 & 26 \\
\hline$\geq 50$ years & 57 & 28 & 29 \\
\hline Regular check up (N,\%) & $220(87.3 \%)$ & $98(85.2 \%)$ & $122(89.1 \%)$ \\
\hline Underlying disease $(\mathrm{N}, \%)$ & $16(6.3 \%)$ & $7(6.1 \%)$ & $10(7.3 \%)$ \\
\hline Hypertension & 11 & 5 & 6 \\
\hline Dyslipidemia & 7 & 3 & 4 \\
\hline Family history DM (N,\%) & $101(40.1 \%)$ & $48(41.7 \%)$ & $53(38.7 \%)$ \\
\hline Dietary control (N,\%) & $157(62.3 \%)$ & $73(63.5 \%)$ & $84(61.3 \%)$ \\
\hline Regular exercise (N,\%) & $106(42.1 \%)$ & $47(40.9 \%)$ & $59(43.1 \%)$ \\
\hline Current smoker $(\mathrm{N}, \%)$ & $44(17.5 \%)$ & $7(6.1 \%)$ & $37(27.0 \%)$ \\
\hline Current alcoholic (N,\%) & $89(35.3 \%)$ & $23(20 \%)$ & $66(48.2 \%)$ \\
\hline Pregnancy (N,\%) & & $47(40.9 \%)$ & \\
\hline Prior GDM & & $5(10.6 \%)$ & \\
\hline Child $>4 \mathrm{~kg}$ & & $2(4.3 \%)$ & \\
\hline BMI $\left(\mathrm{kg} / \mathrm{m}^{2}\right.$, mean $\left.\pm \mathrm{SD}\right)$ & $24.7 \pm 5.91$ & $23.9 \pm 6.31$ & $25.4 \pm 5.48$ \\
\hline $\mathrm{SBP}(\mathrm{mmHg}$, mean $\pm \mathrm{SD})$ & $133.6 \pm 20.43$ & $129.9 \pm 21.5$ & $136.6 \pm 19.02$ \\
\hline $\mathrm{DBP}(\mathrm{mmHg}$, mean $\pm \mathrm{SD})$ & $78.9 \pm 14.10$ & $77.2 \pm 14.3$ & $80.35 \pm 13.81$ \\
\hline \multicolumn{4}{|l|}{ Laboratory Investigation } \\
\hline Glucose (mg/dL, median [IQR]) & $93.0[84-108]$ & $93.0[85-108]$ & $94.0[82.5-107.5]$ \\
\hline $\mathrm{HbA1c}(\%$, mean $\pm \mathrm{SD})$ & $5.56 \pm 0.73$ & $5.40 \pm 0.70$ & $5.57 \pm 0.75$ \\
\hline $\mathrm{Hb}(\mathrm{g} / \mathrm{L}$, median [IQR]) & $14.5[13.5-15.5]$ & $13.7 \pm 1.61$ & $15.2[14.5-15.9]$ \\
\hline Creatinine (mg/dL, median [IQR]) & $0.88[0.73-1.01]$ & $0.73[0.65-0.81]$ & $0.98[0.89-1.07]$ \\
\hline eGFR (mL/min, median [IQR]) & $95.2[83.7-105.9]$ & $99.7[84.0-108.5]$ & $92.1 \pm 15.3$ \\
\hline \multicolumn{4}{|l|}{ Diabetes Risk Score } \\
\hline Thai (median [IQR]) & $7.0[5-10]$ & $6.0[4.0-9.0]$ & $9.0[5-11]$ \\
\hline ADA (median [IQR]) & $3.0[2.3-4.0]$ & $3.0[2.0-4.0]$ & $4.0[3.0-5.0]$ \\
\hline
\end{tabular}

DM, diabetes; GDM, gestational diabetes; BMI, body mass index; SBP, systolic blood pressure; DBP, diastolic blood pressure; $\mathrm{Hb}$, hemoglobin

Data normally distributed expressed as means \pm standard deviation; non-normally distributed expressed as median [interquartile range] 
Table 3. Correlation between POC HbAlc and diabetes risk scores

\begin{tabular}{lcc}
\hline HbA1c vs & Correlation & $\boldsymbol{p}$-value \\
\hline All individuals & & \\
Thai & 0.226 & $<0.001^{*}$ \\
ADA & 0.279 & $<0.001^{*}$ \\
\hline Female individuals & & \\
$\quad$ Thai & 0.228 & $0.014^{*}$ \\
ADA & 0.249 & $0.007^{*}$ \\
\hline Male individuals & & \\
Thai & 0.233 & $0.006^{*}$ \\
ADA & 0.318 & $<0.001^{*}$ \\
\hline
\end{tabular}

Correlation using two-tailed Pearson's test

* Statistically significance at $p<0.05$

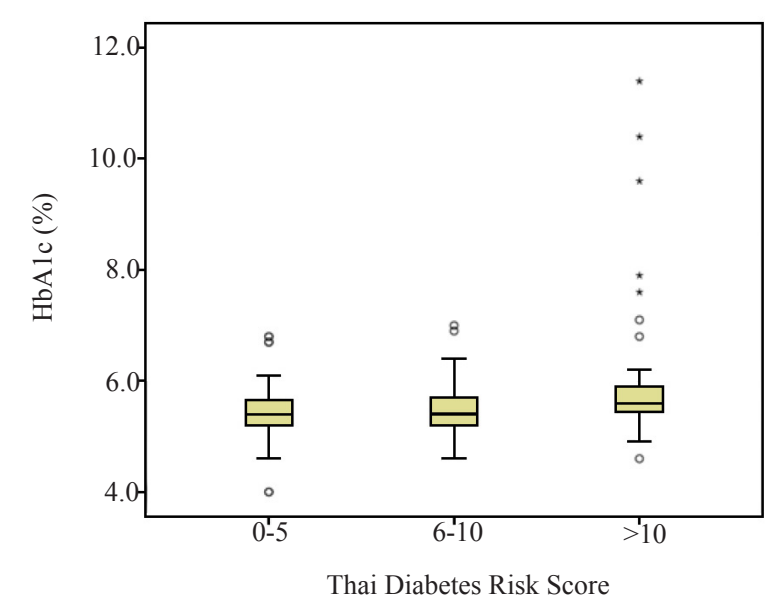

(a)

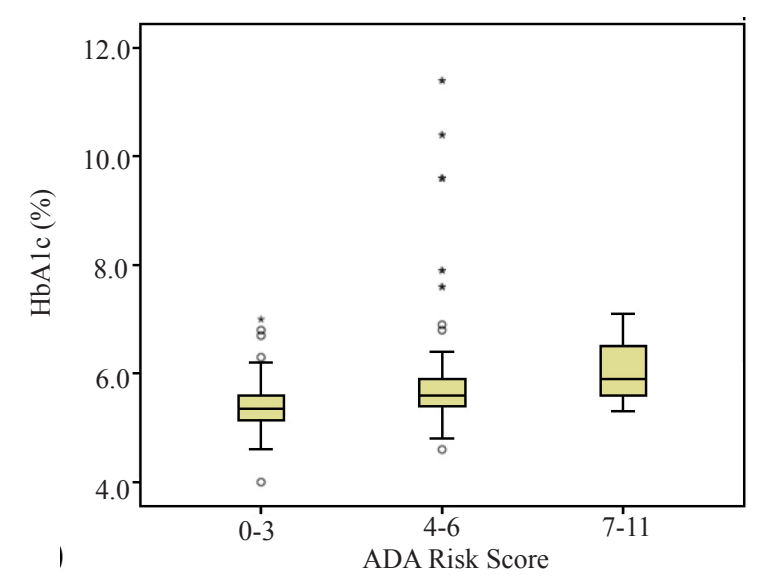

(b)

Figure 1. Changes in median, interquartile range, minimum and maximum $\mathrm{HbAlc}$ values of all participants in the associated risk categories of the (a) Thai diabetes risk score, and (b) ADA diabetes risk score

\section{Correlation between POC HbA1c and diabetes risk scores}

Weak positive correlations between POC $\mathrm{HbA1c}$ and both Thai and ADA diabetes risk scores were observed (Table 3). Subset analysis showed that POC HbAlc correlated with both male and female individuals. Higher correlation was observed when using the ADA risk score.

\section{POC HbA1c values and risk prediction categories}

Increasing diabetes risk scores were associated with higher POC HbA1c. Among all individuals, lower Thai risk scores were associated with lower HbAlc while higher scores were associated with higher HbAlc, many of which appeared outside the 1SD, identified as outliers (Figure 1).
No significant differences were identified between lower and moderate scores using the Thai score. For the ADA risk score, however, individuals with moderate scores (4-6 points) showed the greatest variability in $\mathrm{HbA} 1 \mathrm{c}$ with the highest $\mathrm{HbAlc}$ identified in this subgroup.

Male individuals showed similar findings concerning the analysis among all participants. The median HbA1c for high risk Thai and high risk ADA scores were $5.6 \%$ and $5.9 \%$, respectively (Figure 2). High risk categories other than median HbAlc were highest for both Thai and ADA scores. For females, high risk category was associated with the highest $\mathrm{HbAlc}$. However, no subjects were categorized as high risk. The median HbAlc for high-risk Thai and moderate-risk ADA scores were $5.75 \%$ and $5.7 \%$, respectively (Figure 3). 


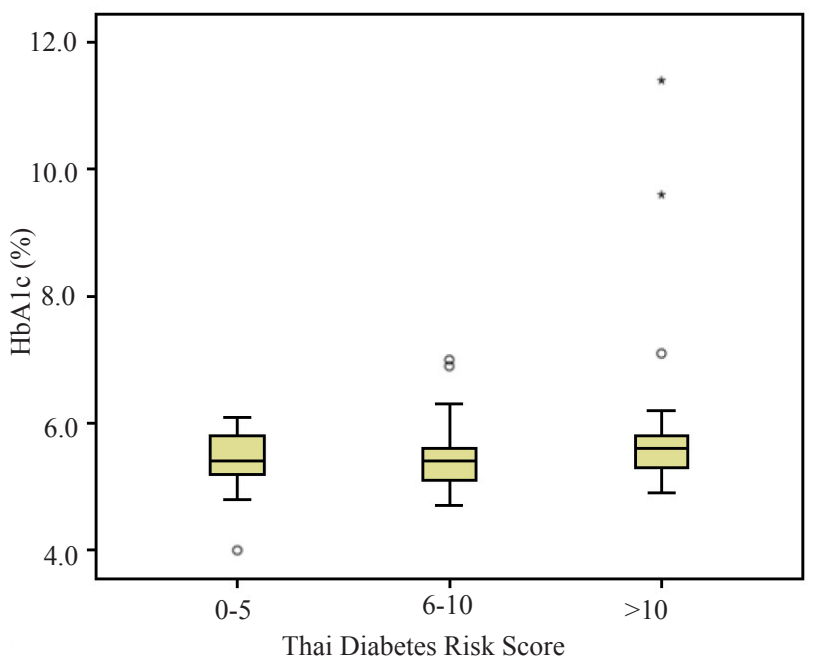

(a)

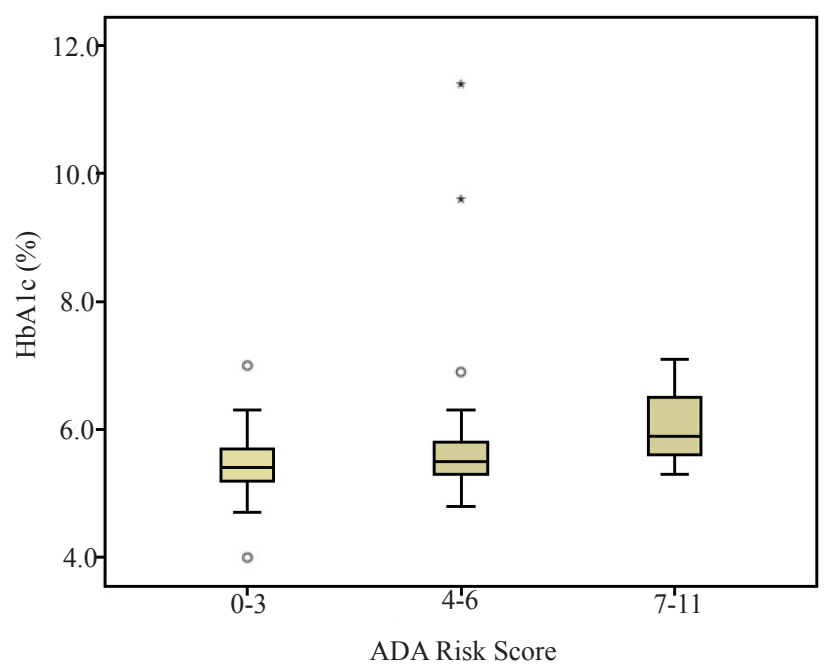

(b)

Figure 2. Changes in median, interquartile range, minimum and maximum $\mathrm{HbA1c}$ values of male participants in the associated risk categories of the (a) Thai diabetes risk score, (b) ADA diabetes risk score

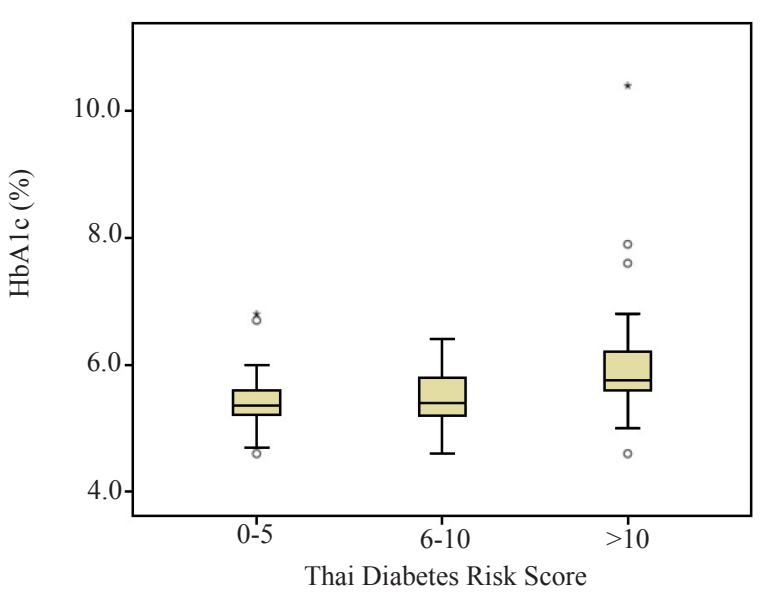

(a)

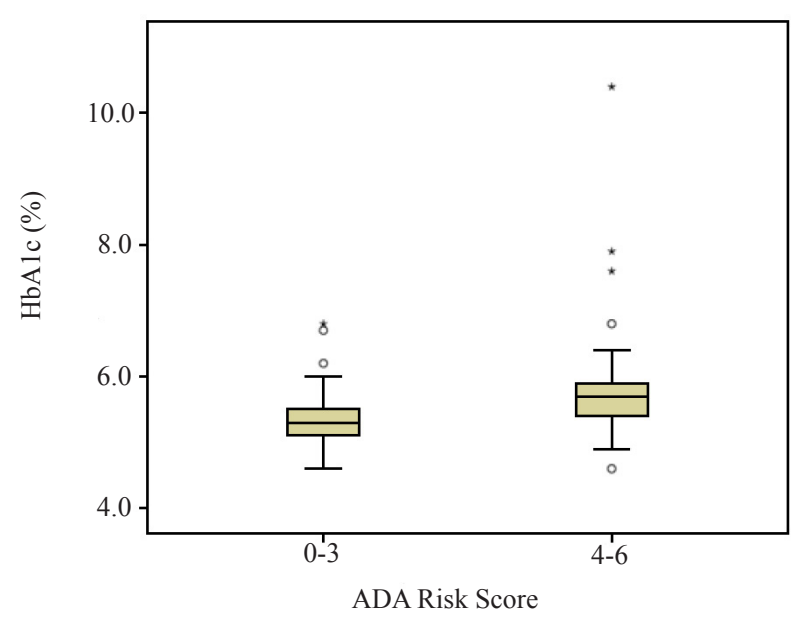

(b)

Figure 3. Changes in median, interquartile range, minimum and maximum $\mathrm{HbA1c}$ values of females in the associated risk categories of the (a) Thai diabetes risk score, (b) ADA diabetes risk score

Further analysis of the associations between $\mathrm{HbAlc}$ and other categorical factors were analyzed. Of all the anthropometric factors, waist circumference $>90 \mathrm{~cm}$ among males $(p=0.016)$, $\mathrm{BMI} \geq 27.5(p=0.002)$, and Thai diabetes risk score $>10(p=0.026)$ were associated with the highest $\mathrm{HbA1c}$. In multivariate analysis, waist circumference and BMI remained associated with high HbA1c.

\section{Discussion}

Early case detection of diabetes has been a key challenge in clinical practices. This study aimed to screen for diabetes in the out-of-clinic setting during blood donation, using diabetes risk scores,
POC HbA1c and plasma glucose. The primary outcome showed a weak positive correlation between POC HbAlc and the Thai diabetes risk score. However, the association between $\mathrm{HbAlc}$ and diabetes risk has long-been established in related studies. ${ }^{(14,15)}$ This constituted the first time that POC HbAlc was used to study the correlation to Thai risk score.

$\mathrm{POC} \mathrm{HbAlc} \mathrm{is} \mathrm{a} \mathrm{relatively} \mathrm{recent} \mathrm{development}$ in testing glycated hemoglobin, using charge and structural differences of red blood cells to differentiate HbAlc values..$^{(9)}$ Although accuracy of POC systems is inferior to traditional blood samples ${ }^{(16-18)}$, they offered greater access to immediate test results. POC $\mathrm{HbAlc}$ has been used 
in a number of countries and has shown benefits in glycemic control. It facilitates treatment intensification by allowing immediate $\mathrm{HbAlc}$ results. ${ }^{(19)}$ This has led to improved HbAlc by $0.5 \%$ over three months. However, paucity of data was found using POC $\mathrm{HbAlc}$ diabetes screening. ${ }^{(20)}$ At the present time, the only US FDA-approved POC $\mathrm{HbAlc}$ is the Afinion HbA1c Dx Assay while many more are in development. Currently, the ADA and Thai guidelines do not recommend using POC $\mathrm{HbAlc}$ instead of $\mathrm{HbA} 1 \mathrm{c}$. Interestingly, a Thai study in testing POC HbAlc among individuals undergoing a dental procedure showed up to $33.8 \%$ of individuals presented POC HbAlc $\geq 5.7 \%$. . $^{(1)}$ In addition, a recent study in Indonesia revealed that the use of POC HbA1c showed potential in diagnosing diabetes with a sensitivity of $97 \%$ and specificity of $77 \%$. $^{(22)}$

One notable strength of this study was comparing Thai and ADA guidelines. The correlations demonstrated the validity of the two risk scores. However, the correlation appeared weak and may reflect on the POC system not being as accurate as the standard HbAlc. The other possibility would be the validity of risk scores themselves as demographics may change over the years, leading to a shift in risk score associations. For this study, comparison of the POC HbAlc and serum $\mathrm{HbAlc}$ was not available and thus might have reflected on the reliability of the POC HbAlc.

The other main difference in the study was using the out-of-clinic design. The majority of evidence in published literature is limited to in-clinic settings. However, the difference should not affect the HbAlc used as the main measure of this study.

Despite the weak correlation observed, one of the notable associations observed in this study were BMI and waist circumference. Obesity is a disease with rising prevalence and has close links with type 2 diabetes and metabolic syndrome. The Study to Help Improve Early evaluation and management of risk factors Leading to Diabetes (SHIELD) and the National Health and Nutrition Examination Surveys (NHANES) showed that increased BMI was associated with increased prevalence of type 2 diabetes, hypertension, and dyslipidemia. ${ }^{(23)}$ For this study, the association of higher HbA1c was likely to be driven by obesity.

Furthermore, the correlations were shown to be more significant in the higher risk group, while the lower risk group showed little difference. Individuals prone to develop diabetes often have multiple factors at play, as well as having IFG, IGT or both as risk enhancers. However, this study was unable to measure fasting glucose or OGTT and hence was unable to confirm this hypothesis. Interestingly, the ADA diabetes risk score showed significant heterogeneity in $\mathrm{HbAlc}$ results while Thai scores did not. This was likely due to fundamentals in the design of the scoring system itself to correlate with a specific population and would suggest that ADA may not be a validated tool for practical use in Thai populations.

Limitations in this study included firstly, the majority of participants did not have fasting glucose levels. General recommendations from the Blood Bank suggest having food before blood donation. Therefore, correlating $\mathrm{HbAlc}$ with FPG was not possible, and subsequently not possible to definitely diagnose diabetes according to the new recommendations from ADA. Secondly, the nature of this cross-sectional design was the lack of causality. Also, unlike related cohorts that could predict future risk of diabetes, this study was not designed to evaluate future risk. Thirdly, the use of POC HbAlc did not have a standard serum $\mathrm{HbA} 1 \mathrm{c}$ to correlate the findings. Related studies have shown that POC HbAlc was comparable to standard $\mathrm{HbAlc}$, albeit with slightly lower accuracy. Adding the standard HbAlc to the protocol would improve the credibility of the data in this study.

In summary, the weak correlations observed in this study may have suggested that the use of POC HbA1c as a screening tool for diabetes in the out-of-clinic setting is less likely to be of benefit.

\section{Conclusion}

Higher Thai diabetes risk score was associated with higher HbAlc. This association was valid for both HbAlc and POC HbAlc. Because of the more rapid test results, $\mathrm{POC} \mathrm{HbAlc}$ may be more suitable for use in-clinic than out-of-clinic 
situations especially among individuals with risk scores $>10$. Higher BMI and waist circumference are predictors of higher POC HbAlc and may warrant earlier and more comprehensive testing.

\section{Disclosures}

The authors declare they have no conflicts of interest.

\section{References}

1. IDF Diabetes Atlas 9th Edition [Internet]. IDF. 2019. Available from: https://www. diabetesatlas.org/en/sections/worldwidetoll-of-diabetes.html.

2. IDF Diabetes Atlas [Internet]. IDF. 2019 [cited December 1, 2019]. Available from: https://diabetesatlas.org/data/en/country/ 196/th.html.

3. Beckman JA, Creager MA. Vascular complications of diabetes. Circulation Res 2016; 118: 1771-85.

4. Alva ML, Gray A, Mihaylova B, Leal J, Holman RR. The impact of diabetes-related complications onhealthcare costs: new results from the UKPDS (UKPDS 84). Diabet Med 2015; 32: 459-66.

5. Clinical Practice Guideline for Diabetes 2017 by Royal College of Physicians of Thailand, $3^{\text {rd }}$ edition 2017.

6. Aekplakorn W, Bunnag P, Woodward M, Sritara P, Cheepudomwit S, Yamwong S, et al. A risk score for predicting incident diabetes in the Thai population. Diabetes Care 2006; 29: 1872-7.

7. Classification and Diagnosis of Diabetes: Standards of Medical Care in Diabetes-2020. Diabetes Care 2020; 43 (Suppl 1): S14-s31.

8. Aekplakorn W, Tantayothai V, Numsangkul S, Sripho W, Tatsato N, Burapasiriwat T, et al. Detecting prediabetes and diabetes: Agreement between fasting plasma glucose and oral glucose tolerance test in Thai adults. J Diabetes Res 2015; 2015: 396505.

9. Kaur J, Jiang C, Liu G. Different strategies for detection of $\mathrm{HbAlc}$ emphasizing on biosensors and point-of-care analyzers. Biosens Bio electron 2019; 123: 85-100.
10. Campbell L, Pepper T, Shipman K. HbA1c: a review of non-glycaemic variables. J Clin Path 2019; 72: 12-9.

11. Penttila I, Penttila K, Holm P, Laitinen H, Ranta $\mathrm{P}$, Torronen J, et al. Methods, units and quality requirements for the analysis of haemoglobin A1c in diabetes mellitus. World $\mathrm{J}$ Method 2016; 6: 133-42.

12. Weykamp C. HbA1c: a review of analytical and clinical aspects. Annals Lab Med 2013 ; 33: 393-400.

13. Saeedi P, Petersohn I, Salpea P, Malanda B, Karuranga S, Unwin N, et al. Global and regional diabetes prevalence estimates for 2019 and projections for 2030 and 2045: Results from the International Diabetes Federation Diabetes Atlas, $9^{\text {th }}$ edition. Diabetes Res Clin Practice 2019; 157: 107843.

14. Thewjitcharoen Y, Jones EA, Butadej S, Nakasatien S, Chotwanvirat P, Wanothayaroj E, et al. Performanceof HbAlc versus oral glucose tolerance test (OGTT) as a screening tool to diagnose dysglycemic status in high-risk Thai patients. BMC Endocr Disord 2019; 19: 23.

15. Gray BJ, Bracken RM, Turner D, Morgan K, Thomas M, Williams SP, et al. Examining the relationship between $\mathrm{HbA} 1 \mathrm{c}$ and diabetes risk models in a European population indicates a lower threshold to identify 'high risk' is required. Diabetes Vasc Dis Res 2016; 13: 228-35.

16. Marley JV, Oh MS, Hadgraft N, Singleton $\mathrm{S}$, Isaacs $\mathrm{K}$, Atkinson D. Cross-sectional comparison of point-of-care with laboratory $\mathrm{HbA}(1) \mathrm{c}$ in detecting diabetes in real-world remote Aboriginal settings. BMJ Open 2015: 5: e006277.

17. Sobolesky PM, Smith BE, Saenger AK, Schulz K, Apple FS, Scott MG, et al. Multicenter assessment of a hemoglobin A1c point-of-care device for diagnosis of diabetes mellitus. Clin Biochem 2018; 61: 18-22.

18. Fellows SE, Cipriano GC. Variation between point-of-care and laboratory $\mathrm{HbAlc}$ testing in clinical practice. P R Health Sci J 2019; 38: 189-191. 
19. Schnell O, Crocker JB, Weng J. Impact of $\mathrm{HbAlc}$ testing at point of care on diabetes management. J Diabetes Sci Tech 2017; 11: 611-7.

20. Whitley HP, Hanson C, Parton JM. Systematic diabetes screening using point-of-care $\mathrm{HbA1c}$ testing facilitates identification of prediabetes. Annals Fam Med 2017; 15: 162-4.

21. Tantipoj C, Sakoolnamarka SS, Supa-amornkul S, Lohsoonthorn V, Deerochanawong C, Khovidhunkit SP, et al. Screening for type 2 diabetes using point-of-care testing for HbAlc among Thai dental patients. Southeast Asian J Trop Med Pub Health 2017; 48: 455-65.
22. Berbudi A, Rahmadika N, Tjahjadi AI, Ruslami R. Preformance of point-of-care testing compared with the standard laboratory diagnostic test in the measurement of $\mathrm{HbAlc}$ in Indonesian diabetic and nondiabetic subjects. J Diabetes Res 2020; 2020: 2037565.

23. Bays HE, Chapman RH, Grandy S. The relationship of body mass index to diabetes mellitus, hypertensionand dyslipidaemia: comparison of data from two national surveys. Inter J Clin Prac 2007; 61: 737-47. 